\title{
La prostitución, rehén permanente del discurso de la trata de personas*
}

\author{
Prostitution, a permanent hostage of discourses on human trafficking
}

\author{
Esther Pomares Cintas \\ Universidad de Jaén \\ epomares@ujaen.es \\ 0001-6533-6873
}

Resumen

La historia de las políticas internacionales represivas del control migratorio contemporáneo brotó con la gestión, en el seno de la Sociedad de Naciones, del éxodo intraeuropeo y transcontinental de mujeres prostitutas europeas de fines del siglo XIX y principios del XX, tildado como "trata de blancas". El análisis de la documentación registrada en los Archivos de la Sociedad de Naciones ha permitido escrutar las claves de las agendas políticas internacionales en torno a la trata de personas que se fraguaron a merced de aquella realidad migratoria de mujeres. Revelan significativas cuestiones de fondo: la forja de un ideario que toma con fuerza la prostitución como rehén de un discurso de la trata de personas tendente a discapacitar a mujeres adultas en el ámbito de la prestación voluntaria de servicios sexuales retribuidos, como medida para erradicar la prostitución como oportunidad laboral que facilita migrar. Dado que los flujos migratorios de cuadros no cualificados y empobrecidos no cesarán, porque los factores que los impulsan tienen vocación de permanencia, el viejo discurso político retorna hoy sobre sus pasos: se vuelve a situar el trabajo sexual en el paradigma de un concepto de trata de personas entendido como herramienta de contención de flujos migratorios "molestos", bajo un fundamento reduccionista y especulativo que identifica la trata con la prostitución (Resolución del Parlamento Europeo de 26 de febrero de 2014). Analizaremos pormenorizadamente las claves de este discurso y su impacto en la actualidad.

\footnotetext{
* Este trabajo se enmarca en los Proyectos de investigación "Esclavitud contemporánea y trata de personas en el contexto internacional, nacional y andaluz: un estudio jurídico multidisciplinar y transversal" (P18-RT-2253P), Universidad de Granada; y "Los delitos contra la libertad e indemnidad sexual: solución a los problemas prácticos” (Ref. PGC2018-098549-B-100), Universidad de Granada.
} 
Palabras clave: Trata de personas, control migratorio, prostitución, victimización

\begin{abstract}
The history of repressive international policies to control migratory flows of unqualified economic immigrants emerged within the League of Nations at the turn of the 20th century, with the management of the intra-European and transcontinental exodus of prostitutes, known as "white slave trade". As the Archives of the League of Nations reveal, some of the keys of the international political agendas on human trafficking at the time were forged around women. They reveal, in particular, that prostitution was taken hostage to a discourse on trafficking in human beings, aimed at eradicating prostitution as a job opportunity for migrant women. As the migratory flows of unqualified and impoverished people are not likely to cease, since the factors that drive them appear to be here to stay, old political discourses are retracing their steps. Sex work is once again contemplated from the prism of the fight on trafficking in human beings, understood in turn as a tool for containing "annoying" migratory flows. This points to a reductionist and speculative aim: we must "avoid the idea that prostitution can be a solution for migrant women in Europe" (European Parliament resolution of 26 February 2014). Analising in detail the keys and impact of this discourse is the purpose of this article.
\end{abstract}

Key words: Trafficking in human beings, migration control, prostitution, victimization. 


\section{Introducción}

La presencia de mujeres extranjeras, que encuentran en la prostitución una oportunidad laboral cierta que les posibilita migrar, se ha comprendido y reconducido estratégicamente, desde el marcado fenómeno migratorio intraeuropeo y transcontinental de prostitutas europeas entre fines del siglo XIX y principios del XX, a través del discurso de la Trata internacional de personas, originariamente denominado "trata de blancas" y después "trata de personas con fines de explotación sexual". La gestión política de tales desplazamientos transnacionales de mujeres determinaría la de futuros flujos migratorios laborales semejantes -de sectores no cualificados y empobrecidos- a escala internacional.

En aquel entonces se abría un contexto de crisis de postguerra, caracterizado por el proteccionismo económico a ultranza, el auge del puritanismo y la restricción de los cupos de inmigración (Fontana, 2017, pp. 133 ss; Zweig, 2001, pp. 98 ss). Contemplar, por lo general, un perfil migratorio consentido o voluntario de trabajadoras sexuales extranjeras planteaba cuestiones que no eran fáciles de abordar ni comprender. ¿Aquello podía identificarse con la Trata de personas? ¿Qué medidas había que tomar?

Esta realidad, sus características principales, los prismas desde los que se analiza, los desafíos que plantea y su impacto político, se sacan a la luz a través del examen minucioso del material registrado en los Archivos de la Sociedad de Naciones - Biblioteca de Naciones Unidas en Ginebra- Ilevado a cabo por el sociólogo belga de la Universidad de Lovaina, J.-M. Chaumont (2009).

La envergadura, idiosincrasia y repercusión social y económica de aquel movimiento de "prostitución migrante" de mujeres, generalmente mayores de edad, brindaron, en un periodo agudo de crisis, la coyuntura políticamente propicia para plantear, a escala internacional, la oportunidad de elaborar un nuevo marco normativo mundial. El objetivo era arbitrar instrumentos que permitieran mirar aquel escenario impactante -por la condición de mujeres- prostitutas- migrantes- a través de la voz malsonante Trata de personas; una herramienta terminológica necesaria para gestar y armar la estrategia, también a nivel internacional: implementar medidas de contención y represión de desplazamientos transfronterizos ante un pronóstico de reiteración de flujos migratorios laborales de ese calado (inmigración económica no cualificada de sectores empobrecidos).

Para ello había que asentar primero las bases que pusieran en marcha una maniobra maestra de metamorfosis conceptual, de conversión de un escenario de "prostitución migrante" voluntaria de mujeres en una plataforma de Trata de mujeres con fines de explotación sexual. Y brindar, en consecuencia, una salida política que permitiera reprimir y contener flujos migratorios de ese perfil.

Cuestión crucial fue, pues, el desafío al que se enfrentaba el Comité especial de Expertos sobre la Trata de mujeres y niños, nombrado por el Consejo de la Sociedad de Naciones, y compuesto por 8 miembros (mujeres y hombres) de distintas nacionalidades (Bélgica, Estados Unidos, Francia, Italia, Japón, Reino Unido, Suiza y Uruguay). El análisis de la documentación registrada en los Archivos ha permitido escrutar las claves de la metamorfosis conceptual de la Trata que se fraguó a merced del estrépito de aquella realidad migratoria de mujeres. Revela las cuestiones de fondo abordadas por el Comité de expertos, los contextos, sus protagonistas, plasmados detalladamente en documentos, estudios y actas de las deliberaciones e intervenciones de sus miembros a lo largo de 74 reuniones, distribuidas en 7 periodos de sesiones, entre abril de 1924 y noviembre de 1927 (Chaumont, 2009, 
pp. 64-65). El informe, distribuido en dos partes, se elevó al Consejo de la Sociedad de Naciones entre 1927 y 1928.

Este proceso de transformación ha ido forjando un ideario que ahora toma con fuerza la prostitución como rehén del nuevo discurso de la Trata de personas, tendente a discapacitar a las mujeres adultas en el ámbito de la prestación de servicios sexuales como maniobra para desterrar la prostitución como vía laboral que facilita migrar.

La retórica de aquel Comité, plasmada en sus deliberaciones, es el legado de la visión contemporánea de la Trata de personas y de su funcionalidad integrada en las políticas internacionales de control de los actuales flujos migratorios.

Veamos entonces las claves de este discurso y su impacto en la actualidad.

\section{El impacto de una prostitución migrante de mujeres y su gestión política en la Sociedad de Naciones}

Entre fines del siglo XIX y principios del siglo XX, se abre un intenso periodo de desplazamientos migratorios de mujeres europeas de distinta procedencia ${ }^{1}$, en su mayoría prostitutas en el país de partida ${ }^{2}$, tanto dentro de Europa como de alcance transcontinental -así, hacia Norteamérica y algunos países iberoamericanos ${ }^{3}$.

En aquel significativo periodo histórico, la reglamentación de la prostitución, sin perjuicio de sus particularidades y variantes, se hallaba extendida en gran parte del continente europeo y también del americano ${ }^{4}$. Sin embargo, en distintos países europeos, el número de locales de prostitución disminuyó considerablemente, y luego drásticamente tras la Primera Guerra Mundial. En casi toda Europa, la prostitución ya no ofrecía recursos suficientes para vivir (cifr. Chaumont, 2009, pp. 51, 104), lo que precipitó un cambio de destino geográfico de mujeres que, manteniendo la misma ocupación, buscaban mejorar sus condiciones de vida. El éxodo de prostitutas extranjeras se incrementó hacia otros continentes, especialmente el americano ${ }^{5}$. La inmensa mayoría de las mujeres trabajadoras desplazadas (y adultas), se dirigía, a través de la intermediación de terceros que les facilitaban burlar los controles fronterizos y/o su colocación, hacia países en los que existía reglamentación de la prostitución o se toleraba, como una opción posible para migrar (cfr. Chaumont, 2009., pp. 68-69, 70).

\subsection{Dilemas que plantea}

La envergadura e idiosincrasia de un movimiento de "prostitución migrante" de mujeres, generalmente mayores de edad -es decir, mayores de 20 o 21 años, según la legislación internacional

\footnotetext{
${ }^{1}$ Sobre todo, polacas, rusas, rumanas, alemanas, francesas. Cfr. Chaumont, 2009, p. 115.

${ }^{2}$ También bailarinas de cabaret y otras categorías laborales, véase la Primera parte del Informe del Comité especial de expertos sobre la Trata de mujeres y niños (pp. 20, 23). Cfr. Chaumont, 2009, pp. 68, 71.

${ }^{3}$ México, Argentina, Uruguay. También se desarrolló un segundo itinerario de mujeres europeas a Egipto y países del Norte de África, como Túnez, por parte de prostitutas francesas. Cfr. Chaumont, 2009, pp. 24, 68. Véase también, Maqueda Abreu, 2007, pp. 295 ss.

${ }^{4}$ Desde mediados del siglo XIX en gran parte de los países europeos y, a principios del siglo XX, también en América del Norte, "todavía se toleraba con carácter general la prostitución". Cfr. Vlillacampa Estiarte, 2012, pp. 3, 10. Vid. Zweig, 2001, pp. 117 ss.

${ }^{5}$ Ese estado de cosas se refleja en las reuniones del Comité de expertos en el Sexto Período Sesiones. Cfr. Chaumont, 2009., pp. 114, 143.
}

Revista del Laboratorio Iberoamericano para el Estudio Sociohistórico de las Sexualidades 176 https://doi.org/10.46661/relies.XXXX 
vigente en 1910 y 1921, respectivamente ${ }^{6}$-, suscitó una grave preocupación a escala internacional, suficiente como para tildarlo de "fenómeno" de repercusiones socioeconómicas, un problema migratorio "realmente grave" (primera parte del Informe del Comité de expertos, p. 49 -cfr. Chaumont, 2009, p. 142-). Constituyó el enclave propicio para supervisar, desde la Sociedad de Naciones, la aplicabilidad del marco internacional vigente sobre la denominada Trata de blancas. El hecho de ser, por lo general, como se vera más adelante, desplazamientos transnacionales consentidos, de trabajadoras sexuales extranjeras, facilitados por terceros o intermediarios, planteaba cuestiones que no eran fáciles de abordar ni comprender desde la normativa existente.

En efecto, el primer paso fue actualizar la denominación "trata de blancas" empleada por los Convenios internacionales para la represión de la Trata de blancas, de 18 de mayo de 1904, y de 4 de mayo de 1910, anteriores a la conformación de la Sociedad de Naciones. Se otorga carta de naturaleza a una nueva denominación, en virtud del Convenio internacional para la represión de la Trata de mujeres y niños, de 30 de septiembre de 1921, que pasa a formar parte del acervo normativo de la Sociedad de Naciones.

Sin embargo, este instrumento se limita a reproducir el contenido del anterior (1910), pues no se había previsto entonces modificar el concepto de Trata internacional de mujeres: solamente eleva la mayoría de edad a los 21 años cumplidos (art. 5). A través de cláusulas de remisión expresa, el Convenio de 1921 (arts. 2 y 3) confirma la vigencia de la definición de Trata prevista en el de 1910, que pretende mantener, sin desvirtuar su sustrato, los elementos que caracterizan la Trata de esclavos -abusivos, coercitivos, violentos o engañosos-, pensando, asimismo, en las hipótesis de efectiva "retención, contra su voluntad, de una mujer o una joven en una casa de prostitución"7 .

Artículo 2 (Convenio de 1910): Debe ser castigado cualquiera que, para satisfacer las pasiones de otro, mediante fraude o violencia, abuso de autoridad o cualquier otro medio de coacción, contrate, secuestre o seduzca a una mujer o una joven mayor de edad, con propósitos sexuales, aun cuando los diversos actos constitutivos de la infracción hayan sido cometidos en países diferentes ${ }^{8}$.

Es decir, la regulación legal vigente en aquel tiempo no separa el concepto de Trata de personas de su esencia como antesala de un destino explotador asimilado a la esclavitud. Es un marco internacional que reconoce a las mujeres mayores de edad capacidad de decidir libremente, concibiendo en un plano distinto de la Trata y la esclavitud sexual la cuestión de la prostitución y su reglamentación, como esfera de emancipación.

La Sociedad de Naciones creó, a la sazón, una Comisión consultiva permanente que, en la sesión de 24 de marzo de 1923, planteó al Consejo tres cuestiones clave a propósito de ese escenario migratorio de prostitutas europeas. En primer lugar, si encarna realmente un retorno contemporáneo de la Trata de esclavos, es decir, si es posible afirmar la existencia entre Europa y América de una Trata internacional de mujeres con la finalidad de ser prostituidas, en virtud de la concepción de los Convenios de 1910 y 1921; en segundo lugar, dado que intervienen terceros en

\footnotetext{
${ }^{6}$ La mayoría de edad se alcanzaba a los 20 años, según el Convenio internacional de 4 de mayo de 1910 para la represión de la trata de blancas; se elevó a los 21, conforme al Convenio internacional de 30 de septiembre de 1921 para la represión de la trata de mujeres y niños.

${ }^{7}$ Apartado D, Anexo Protocolo de Clausura del Convenio de 1910, que forma parte integrante del mismo. El Preámbulo del Convenio de 18 de mayo de 1904 para la represión de la trata de blancas también menciona, respecto de las mujeres mayores de edad, los términos de abuso o coerción en orden a la prestación de servicios sexuales.

${ }^{8}$ Plantea una tipificación distinta cuando la víctima es menor de edad. Artículo 1: Debe ser castigado cualquiera que, para satisfacer las pasiones de otro, haya contratado, secuestrado o seducido, aun con su consentimiento, a una mujer o a una joven menor de edad, con propósitos licenciosos, aun cuando los diversos actos constitutivos de la infracción se hayan cometido en países diferentes.
}

Revista del Laboratorio Iberoamericano para el Estudio Sociohistórico de las Sexualidades 177 https://doi.org/10.46661/relies.XXXX 
la operación transfronteriza, se insta a analizar el método de reclutamiento de mujeres y su traslado; y, por último, qué medidas serían las idóneas y eficaces, a escala internacional, para controlar y reprimir ese perfil de desplazamientos transnacionales (cfr. Chaumont, 2009, pp. 57, 66).

Para dar respuesta a estas interrogantes, se creó un Comité especial de Expertos sobre la Trata de mujeres y niños, compuesto por 8 miembros (mujeres y hombres) de distintas nacionalidades (cfr. Chaumont, 2009, pp. 10, 12 y ss, 63 y ss.).

Los estudios encargados por la Comisión para analizar en el terreno las características del éxodo intraeuropeo y transcontinental de prostitutas europeas ${ }^{9}$ no arrojaban, según los parámetros internacionales entonces vigentes (Convenios de 1910 y 1921), un diagnóstico de Trata de personas en la gran mayoría de las mujeres que lo protagonizaron en aquel momento histórico; tales desplazamientos no se apoyaban, por regla general, en el forzamiento, coerción, engaño o abuso sobre las mujeres; no fueron obligadas por terceros a salir del país ni a ejercer la prostitución en otro. En suma, no es el retrato de un desplazamiento transfronterizo de mujeres para ser sometidas a servicios sexuales forzados, a una explotación en condiciones asimiladas a la esclavitud como su destino inmediato ${ }^{10}$. Los casos que se habían detectado bajo esas terribles características eran anecdóticos, es decir, residuales ${ }^{11}$, no resultaban suficientes para conformar un fenómeno criminal de Trata internacional a gran escala.

Era evidente que la visión de la Trata de personas, actualizada en el Convenio internacional de 30 de septiembre de 1921 para la represión de la trata de mujeres y niños, se mostraba incapaz de dar respuesta a una modalidad de desplazamientos de mujeres extranjeras que apuntaba a ser otra cosa: una nueva realidad, un fenómeno humano de dimensión socioeconómica, que distaba de ser aprehendido como símil de trata de esclavas (sexuales). En consecuencia, en su gran mayoría, las mujeres involucradas en los traslados transfronterizos no podían ser consideradas víctimas de Trata en sentido estricto del término ${ }^{12}$, se dirigían hacia países en los que existía reglamentación de la prostitución, como una opción posible para migrar (cfr. Chaumont, 2009, pp. 29, 30, 77): eran, por lo general, migraciones laborales consentidas.

En suma, no era posible abordar el fenómeno objeto de investigación desde los instrumentos internacionales vigentes ${ }^{13}$. Ahora bien, siendo consciente el Comité especial de Expertos de este estado de cosas, y aparcando la voluntad política de analizar si el sistema de reglamentación de la prostitución pudo influir en ese diagnóstico general (ausencia de trata y de explotación esclava), el discurso se traslada a otro nivel, pues otros son los objetivos que se pretendía alcanzar en un contexto socioeconómico de proteccionismo a ultranza y férreo control de la inmigración: abrir la puerta a la gestión y contención represiva de flujos migratorios molestos. Era el momento propicio para implicar el ejercicio de la prostitución en un paradigma distinto.

La única voz discordante del grupo de expertos, la única voz reivindicativa de un debate sereno y riguroso, la encarnaba el experto francés, Félicien J.L. Hennequin, presidente de la Asociación francesa para la represión de la trata de mujeres, pues insistía en que el

\footnotetext{
9 Particularmente influyentes fueron los análisis empíricos de Abraham Flexner (1914), y George. J. Kneeland (1913, edición actualizada en 1917).

${ }^{10}$ Se refleja en las deliberaciones que se desarrollan durante el Segundo periodo de sesiones del Comité. Cfr. Chaumont, 2009, pp. 89 ss.

${ }^{11}$ Así lo pone de relieve el análisis de Flexner (1914, p. 93), que fue referente para el Comité de expertos, como se manifiesta en la Primera parte del Informe (pp. 11, 20). Cfr. Chaumont, 2009, pp. 70 ss., 88, 188-190.

12 No se podía concebir como una "verdadera organización internacional que tuviera por objeto favorecer la trata". Primera parte del Informe (p. 27). Cfr. Chaumont, 2009, p. 70.

${ }^{13}$ Así se reconocía en la Primera parte del Informe y también en las deliberaciones del Sexto periodo de sesiones. Cfr. Chaumont, 2009, pp. 67, 142, 143.
}

Revista del Laboratorio Iberoamericano para el Estudio Sociohistórico de las Sexualidades 178 https://doi.org/10.46661/relies.XXXX 
fenómeno migratorio que se analizaba "no es trata propiamente dicha", dado que no se apoya en el forzamiento, engaño o abuso sobre las mujeres, ni su destino laboral era esclavo ${ }^{14}$. Esa "voz de la conciencia" del Comité pronto se apagó. Su muerte allanó el camino del consenso necesario para adoptar el Informe final ${ }^{15}$.

El sistema reglamentado de la prostitución se convierte ahora en foco de atención por considerarse factor de atracción de tales movimientos migratorios, porque favorece la presencia de prostitutas extranjeras en otros territorios.

\subsection{Metamorfosis del concepto de trata de mujeres}

El Comité especial de Expertos sobre la Trata de mujeres y niños de la Sociedad de Naciones no tardó en aprovechar esa coyuntura para eliminar obstáculos terminológicos que, hasta entonces, no permitían adoptar decisiones políticas de significativo alcance en la gestión de flujos migratorios molestos distintos de la Trata de esclavos. Para dar una respuesta positiva a las interpelaciones planteadas al Consejo de la Sociedad de Naciones sobre la existencia de Trata de prostitutas entre Europa y América, el Comité tomó, bajo el manto del consenso, la decisión de envolver el fenómeno que se estaba produciendo en "papel de Trata", a modo de comercio de mujeres para su explotación sexual $^{16}$, para proponer aplicar finalmente medidas de combate y prevención de lo que se deseaba calificar como "fenómeno criminal internacional" (cfr. Chaumont, 2009, p. 76).

Para remover el "obstáculo" derivado de la aplicación de la normativa vigente sobre la Trata y poder escrutar aquel fenómeno bajo el "diagnóstico" de otra noción de "trata" (segundo periodo de sesiones del Comité -cfr. Chaumont, 2009, p. 89-), el Comité aprovechó e instrumentalizó el tirón mediático de los movimientos abolicionistas ${ }^{17}$-especialmente, la Federación abolicionista internacional, y organizaciones privadas no gubernamentales colaboradoras-, que también emprendían su propia cruzada, precisamente al calor de la conmoción social de una prostitución migrante, bajo un ideario que se centraba principalmente en valores de higiene social europea y norteamericana de la época (cfr. Chaumont, 2009, pp. 24 ss., 38, 41 ss). No en vano, la causa abolicionista se encontraba representada en el Comité mismo, e integrada de antemano en el contenido de sus deliberaciones. Entre sus miembros destaca Cristina G. Bandini, princesa italiana fundadora de la Unión de mujeres italianas católicas y miembro de la presidencia de la Unión Internacional de mujeres católicas; Albert De Meuron, evangelista, miembro activo, desde finales del siglo XIX, de la Federación abolicionista internacional; y la médica Paulina Luisi, una de las fundadoras del movimiento abolicionista en Argentina y Uruguay (cfr. Chaumont, 2009, pp. 15-17).

En efecto, se le daba nuevamente voz al ideario abolicionista en el seno de la Sociedad de Naciones, después de ser silenciado con ocasión de la elaboración del Convenio internacional para la represión de la trata de blancas, de 4 de mayo de 1910, un instrumento internacional que resultaba a todas luces incómodo para las posturas abolicionistas, porque separaba materialmente la lucha contra la Trata internacional de mujeres respecto del asunto de la reglamentación de la prostitución, como realidades que debían concebirse en planos conceptuales distintos. La Federación abolicionista internacional no apoyó, por tanto, esta visión de la Trata, y no fue representada en la Sociedad de

\footnotetext{
${ }^{14}$ Debate que se desarrolla durante el Segundo periodo de sesiones del Comité. Cfr. Chaumont, 2009 , pp. 89 ss., 191.

${ }^{15}$ Fue sustituido por el experto francés Pierre Le Luc, quien también se opuso a toda extensión terminológica que quebrara el concepto internacional de trata. Séptimo periodo de sesiones. Cfr. Chaumont, 2009, pp. 91, 95, 194. Esta postura fue finalmente silenciada por la amplia mayoría bajo la fórmula del consenso. Cfr. Chaumont, 2009, p. 65.

${ }^{16}$ Idea subrayada durante el Segundo periodo de sesiones del Comité. Cfr. Chaumont, 2009, p. 89.

${ }^{17}$ Una situación valorativamente inquietante para otros miembros del Comité, como se desprende de las deliberaciones en el Quinto periodo de sesiones, así, el presidente del Comité nacional suizo para la represión de la trata de mujeres, Alfred De Meuron. Cfr. Chaumont, 2009, p. 93.
}

Revista del Laboratorio Iberoamericano para el Estudio Sociohistórico de las Sexualidades 179 https://doi.org/10.46661/relies.XXXX 
Naciones tras la primera Guerra Mundial. Pero volvió enérgicamente sobre sus pasos, precisamente aprovechando la condición de un modo de ser: mujeres- prostitutas- migrantes-. La presencia abrumadora de prostitutas europeas en otros territorios abandera el deterioro de la moralidad del país de origen, que se proyecta al país de destino: ellas representan la degradación psíquica y moral de la especie humana (cfr. Chaumont, 2009, pp. 66, 147, 182). Era, pues, un fenómeno que afectaba a la "higiene social, la moral y del interés del porvenir de la raza" (primera parte del Informe, p. 20 -cfr. Chaumont, 2009, pp. 97-).

Desplegaron una campaña mediática basada en ruido escénico de Trata, una suerte de dramatización que proyectaba al imaginario colectivo europeo y americano los casos aislados o residuales de trata de esclavas sexuales, convertidos ahora en "prácticas generalizadas" (cfr. Chaumont, 2009, p. 33).

Por otro lado, consolidar aquella maniobra terminológica sobre la Trata de personas requería apoyarse en estudios empíricos que corroboraran la necesidad de extender su concepto hacia otra vertiente. El Comité se basó, fundamentalmente, en dos investigaciones impulsadas por el magnate John D. Rockefeller Jr., auspiciadas y financiadas por la Oficina de Higiene Social fundada en Nueva York, presidida por aquél ${ }^{18}$, conducidas, respectivamente, por G. Kneeland (Commercialized Prostitution in New York City, 1913), y A. Flexner (Prostitution in Europe, 1914) ${ }^{19}$.

Ambos estudios centraron la clave de los desplazamientos transfronterizos de mujeres en los sistemas de reglamentación de la prostitución. Y, al tiempo, aportaron otra: la investigación de los datos empíricos se desenvolvió bajo la estela de la normativa norteamericana sobre "trata de esclavas blancas" - White-slave traffic Act, de 25 junio de 1910 (H.R.12315)-, fiel retrato de un contexto socioeconómico de proteccionismo a ultranza, de férreo control de flujos migratorios ${ }^{20}$. Las Secciones 2 y 3 criminalizan el transporte doloso de mujeres mayores de edad (18 años), bien dentro del territorio norteamericano, o bien transfronterizo, hacia otro país, o hacia Estados Unidos (de acuerdo con la aclaración de la Sección 1), para ejercer la prostitución o con otros fines inmorales ${ }^{21}$.

Merced al dogma abolicionista de la época, que identificaba automáticamente la prostitución como forma de esclavitud ${ }^{22}$, y a la crucial influencia de la regulación norteamericana sobre la trata de blancas, que también apostaba por ese dogma, el camino está allanado para gestar un nuevo fenómeno de trata a combatir. Así sobrerrepresentada, se arraigó la convicción de que ese escenario encarnaba una "trata a gran escala y de naturaleza esclavista" (cfr. Chaumont, 2009, p.

\footnotetext{
${ }^{18}$ Precisamente dos de los miembros del Comité de expertos estaban vinculados a la Asociación americana de Higiene social: el presidente del Comité, el médico William F. Snow, también era director de la Asociación. Y Bascom Johnson, director de la sección jurídica de la Asociación de Higiene Social americana, supervisó estos análisis empíricos, por iniciativa de Snow. Cfr. Chaumont, 2009, p. 16, 39 ss.

${ }^{19}$ Sobre sendos estudios empíricos, cfr. Chaumont, 2009, 40 ss., 50 ss. Cuentan con una Introducción a cargo de John D. Rockefeller Jr.

${ }^{20}$ Era un periodo de extremo de conservadurismo y puritanismo en Estados Unidos, también provocado por la crisis económica de postguerra: años de proteccionismo, de cierre de fronteras, de reducción de las cuotas de admisión de inmigrantes, especialmente los europeos del sur. Se percibe una desigualdad creciente, el auge del racismo, y un clima político represivo. Cfr. Fontana, 2017, pp. 133 ss.; vid. detenidamente, Gritner, 1990.

${ }^{21}$ Se castigan estos comportamientos con la pena de multa de hasta 5000 dólares o pena de prisión de hasta 5 años, o ambas. Si la conducta se realiza sobre menores de 18 años, la pena se eleva hasta 10.000 dólares y 10 años de prisión (Sección 4). Sobre la vigencia actual de la incriminación de estos comportamientos en la legislación norteamericana sobre la trata de personas, vid. Villacampa Estiarte, 2012, pp. 11 ss.

22 Los planteamientos abolicionistas eran, en parte, deudores de los valores de la Sociedad Religiosa de Amigos (cuáqueros), que abogaban por la abolición de la esclavitud (representada por Josephine Butler, la fundadora de la Federación abolicionista internacional). Cfr. Chaumont, 2009, p. 38.
}

Revista del Laboratorio Iberoamericano para el Estudio Sociohistórico de las Sexualidades 180 https://doi.org/10.46661/relies.XXXX 
33): se quiso oír "ruido de trata" donde no lo había, una suerte de Trata internacional de mujeres, un ruido que finalmente consiguió acallar las aisladas posiciones críticas en el seno del Comité, que quedaron fagocitadas por el consenso (cfr. Chaumont, 2009, pp. 33 ss).

Al fragor de ese entorno favorable, el Comité de expertos propugnó una concepción de Trata de personas deliberadamente ajena a un contexto de abuso, coerción o violencia en orden a una explotación forzada, que le permitirá sin dificultad recalificar y reprimir cuadros migratorios semejantes bajo la voz contundente de trata de mujeres de un país a otro con el fin de explotación sexual ${ }^{23}$ : a los fines del presente estudio, la trata sexual internacional es definida como el "reclutamiento directo o indirecto y transporte de mujeres a otro país, con ánimo de lucro, para el apetito sexual de una o varias personas" (primera parte del Informe, p. 10 -cfr. Chaumont, 2009, p. 95-).

Objetivo conseguido: el Comité respondió, mediante un ejercicio de contorsionismo, a la primera cuestión que justificó su creación. En nombre de este otro concepto desvirtuado o vacío de Trata, se da respuesta ahora estratégicamente a lo que es más una modalidad de colaboración o favorecimiento de la inmigración irregular de inmigrantes económicos no cualificados ${ }^{24}$ (encarnada entonces en mujeres que encuentran en el ejercicio de la prostitución una oportunidad de migrar cfr. Chaumont, 2009, pp. 28, 34, 113 ss-), que retrata precisamente el perfil contemporáneo de los flujos migratorios laborales, caracterizado por la intervención de terceros en distintas etapas de la operación del desplazamiento transnacional, habida cuenta de las dificultades del traslado y colocación para buscar mejores condiciones de vida.

Aquella definición plástica de Trata, que permite abarcar cuadros migrantes más extensos, era la idónea para justificar y desplegar medidas represivas de distinta índole orientadas a su contención. Veamos.

\subsection{Nuevos dogmas en la agenda política internacional sobre la Trata de mujeres}

Dado que la metamorfoseada visión de la Trata no exige un tejido abusivo o coercitivo sobre la persona desplazada -como enseguida se señalará-, el nuevo dogma que se integra en el ideario del Comité especial de expertos de la Sociedad de Naciones está servido: hay Trata de mujeres porque existe reglamentación de la prostitución. Por ello, de ahora en adelante, la idea de neutralizar los factores de atracción que estimulan perfiles migratorios susceptibles de encuadrarse en el redefinido (y desvirtuado) modelo de trata se coloca en el centro de la agenda política internacional sobre la Trata.

En una época de auge del puritanismo, proteccionismo económico, xenofobia y cierre de fronteras, la influencia de las investigaciones financiadas por la Oficina de Higiene Social norteamericana (los informes de Kneeland y Flexner) marcó las premisas y los objetivos del Comité: el objeto de atención se concentró en el papel de la reglamentación de la prostitución reinante en aquella época y los burdeles o "casas de tolerancia", es decir, el entorno de la prestación de servicios sexuales por cuenta ajena y su demanda, que se instituyó como causa principal y directa de la Trata internacional de mujeres ${ }^{25}$.

Neutralizar ese factor de atracción requería abolirlo en un plano internacional.

\footnotetext{
${ }^{23}$ Segundo periodo de sesiones del Comité. Primera parte del Informe. Cfr. Chaumont, 2009, p. 89.

${ }^{24}$ Véase Attwood, 2016, pp. 115 ss.

${ }^{25}$ Así lo muestran las deliberaciones del Comité durante el Sexto periodo de sesiones. Cfr. Chaumont, $2009, \mathrm{pp} .75,110$. Se concibió como estímulo de la trata internacional en la Primera parte del Informe (p. 54). Cfr. Chaumont, $2009, \mathrm{pp}$. $67,68$.
}

Revista del Laboratorio Iberoamericano para el Estudio Sociohistórico de las Sexualidades 181 https://doi.org/10.46661/relies.XXXX 
Por tanto, la mirada se reorienta hacia el sistema reglamentado de la prostitución, en tanto en cuanto favorece o facilita la presencia de prostitutas extranjeras en otros territorios. La razón era clara: había que erradicar la concepción del ejercicio de la prostitución como una oportunidad posible o lícita para migrar (segundo período de sesiones -cfr. Chaumont, 2009, p. 89-).

En realidad, esa vinculación entre Trata de personas y reglamentación de la prostitución se antoja trivial, retroalimentada por los dogmas de los movimientos abolicionistas de la época, a cuyo ideario paralelo, originariamente puritano y moralista, se daba entrada ${ }^{26}$. Téngase en cuenta que si los desplazamientos de mujeres para ser sometidas a una explotación sexual forzada (servicios forzados) fueran el objeto directo de persecución, no cabría mantener en absoluto una conexión semejante entre una Trata entendida como antesala de un destino explotador esclavo y la reglamentación de la prostitución o la prostitución misma ${ }^{27}$.

Tras este dogma incorporado al acervo del Comité especial de expertos sobre la Trata de mujeres, quedaron colmadas las interrogantes formuladas al Consejo de la Sociedad de Naciones. Se consigue, pues, instrumentalizar también la reivindicación de los movimientos abolicionistas de globalizar la derogación de la reglamentación de la prostitución y la desaparición de los locales de prostitución. Objetivo logrado: se incorpora como asunto prioritario a la agenda política internacional sobre la prevención de la Trata de mujeres y, con ello, se elude automáticamente todo debate sobre las ventajas o inconvenientes de tal o cual sistema de regulación de la prostitución o sobre hipotéticas modificaciones de otros modelos ${ }^{28}$.

Restaba la última de las cuestiones: elaborar medidas eficaces de contención y combate contra la nueva modalidad de Trata internacional de personas.

\section{Medidas de combate, en nombre de la Trata, contra la presencia de mujeres- migrantes-prostitutas}

A partir de la nueva visión de Trata internacional de personas y el "consecuente" dogma -hay Trata porque hay reglamentación de la prostitución-, se incluye por vez primera en el ideario del Comité $y$, de ahora en adelante, en la agenda política internacional en esta materia, la iniciativa de neutralizar los factores de atracción que estimulan los perfiles migratorios encuadrados en el redefinido modelo de Trata. En otras palabras, la prevención de la Trata concebida como fin en sí misma se coloca en el centro.

Desde el reduccionismo político de los debates y de los conceptos, desterrar la idea del ejercicio de la prostitución como trabajo, como oportunidad laboral para salir de un país y entrar en otro, se convierte en llave política para abrir la puerta a planteamientos represivos en un doble eje: la criminalización del entorno de la prostitución, plataforma, a su vez, de la gran estrategia global: la criminalización de la operación migratoria. El objetivo último buscaba gestar e implementar medidas represivas de control y contención de los flujos migratorios laborales contemporáneos (personas en riesgo de exclusión socioeconómica).

\footnotetext{
${ }^{26}$ En este contexto, la fundadora de la Federación abolicionista internacional, Josephine Butler, mantenía en 1869 que el sistema de reglamentación de la prostitución favorecía claramente la trata internacional de prostitutas. Cfr. Chaumont, 2009, pp. 7, 8 ss., 41 ss.

27 Precisamente, en el Sexto periodo de sesiones, algunos de los expertos del Comité ponían en cuestión la estrecha vinculación entre prostitución y trata, hasta el punto de considerarla una visión "exagerada", como manifestaba tempranamente, en el Primer periodo de sesiones, el experto francés, F. J.L. Hennequin. Cfr. Chaumont, 2009, pp. 105, $111,112$.

${ }^{28}$ Como ponía de relieve, en el Tercer periodo de sesiones, el experto francés, Hennequin, el único que se desvinculaba de la tendencia mayoritaria dogmática del Comité. Cfr. Chaumont, 2009, p. 106.
}

Revista del Laboratorio Iberoamericano para el Estudio Sociohistórico de las Sexualidades 182 https://doi.org/10.46661/relies.XXXX 


\subsection{La criminalización internacional del entorno del ejercicio de la prostitución y del perfil de los desplazamientos migratorios contemporáneos}

Pues bien, la coyuntura que ofrecían los movimientos abolicionistas despejó el camino del Comité para orquestar, desde la Sociedad de Naciones, el combate contra la reglamentación de la prostitución. La conexión entre mujeres-inmigrantes y prestación de servicios sexuales en otro país se empieza a concebir así tras el cristal de la represión. Los burdeles se transforman en campo clave criminológico por sus efectos de atracción del nuevo cuadro migratorio que se pretende inhibir en nombre de la Trata. Había que castigar el trabajo sexual por cuenta ajena en todas sus formas, ahora bajo el término global explotación sexual (primera parte del Informe del Comité, p. 53, y sexto periodo de sesiones -cfr. Chaumont, 2009, pp. 265, 123-), determinado por su íntima conexión dogmática con la Trata de mujeres (la nueva concepción), es decir, sin necesidad de hacer gravitar la criminalización en la exigencia de coerción, abuso o engaño sobre la persona que presta servicios sexuales: nuevas figuras penales de índole actuarial, nuevos protagonistas, una "nueva clase de delincuencia" internacional, se introducen con ocasión del discurso de la Trata (cfr. Chaumont, 2009, p. 264) ${ }^{29}$.

Pero no sólo ese entorno se vio gravemente estigmatizado a nivel internacional. La redefinición de la trata transnacional fue tan solo la primera herramienta metodológica del Comité para formular una política represiva mucho más ambiciosa, de alcance general: abrir paso a la criminalización, también a escala internacional, de las vertientes o fases de un proceso migratorio del perfil que se analizaba. De este modo, el interés del control, contención y represión de los nuevos flujos migratorios de personas en riesgo de exclusión socioeconómica deviene en objetivo político central del discurso de la Trata.

El ideario de la Trata se transforma entonces en un juego de palabras deliberadamente utilizadas bajo un eco mercantil: tras la voz "trata de mujeres", se incrimina "cualquier medio empleado (...) para facilitar la prostitución" (quinto periodo de sesiones -cfr. Chaumont, 2009, p. 93-) y, con ello, un "tráfico" transnacional de mujeres que ejercerían la prostitución en otro país. Se pone el acento en la finalidad de explotación sexual "comercial", que no se identifica necesariamente con la prestación forzada de servicios sexuales por cuenta ajena, con la concurrencia de elementos de abuso o coerción que doblegan la voluntad de la víctima en relación con la prestación sexual. No es un escenario de trata de esclavas (sexuales) el objeto de persecución, las modalidades de explotación asimiladas a la esclavitud nunca desempeñaron un papel de fondo ni definidor del alcance de la trata desde el ideario del Comité.

En este nuevo contexto, el "traficante" sería más un pasador de fronteras, o bien "una suerte de agente de colocación" en servicios de prostitución. Por tanto, a partir de finales de la segunda década del siglo XX, se propone etiquetar, con efectos globales, nuevos delitos y delincuentes a los que se aplica la terminología propia del hampa y del crimen organizado: "traficantes", "proxenetas" (Todos son traficantes. Primera parte del Informe, p. 28 -cfr. Chaumont, 2009, p. 267-), que se persiguen en la medida en que su comportamiento favorece aquellos desplazamientos de migrantes objeto de contención. En definitiva, se recalifica aquel éxodo de prostitutas europeas como fenómeno criminal organizado con la finalidad de explotación sexual (desde el Primer periodo de sesiones del Comité -cfr. Chaumont, 2009, p. 90-).

${ }^{29}$ Vid. Caruso Fontán, 2011, pp. 31 ss; Iglesias Skulj, 2012, pp. 13 ss.

Revista del Laboratorio Iberoamericano para el Estudio Sociohistórico de las Sexualidades 183 https://doi.org/10.46661/relies.XXXX 


\subsection{La conformación de un nuevo estatuto de víctimas}

La idea es conformar nuevas víctimas de Trata, que no lo serían desde el punto de vista estricto de los Convenios internacionales de 1910 y 1921, bajo un estatuto particular: desvincular el concepto de Trata de todo elemento coercitivo, abusivo o fraudulento en relación con el desplazamiento y la prestación sexual significa automáticamente arrebatar a las mujeres, por su condición de mujeres, su capacidad de decisión en esferas de emancipación (que también se eliminan) como si fueran menores de edad, bajo el espejismo especulativo de ser mujeres en manos de unos y otros: traficantes, explotadores. Un lenguaje permanente de mercancías -demanda, oferta de servicios, importación o exportación de personas, país de procedencia, tránsito o destino-, derivado de la trata de esclavos y, sin embargo, ahora ajeno a ella, para restar capacidad de decidir a las mujeres migrantes (Maqueda Abreu, 2009, pp. 1251 y ss).

Dado que no se requiere doblegar la voluntad de la mujer para hablar de Trata, y que es posible, como mostraban los estudios encargados por el Comité, que las nuevas víctimas de Trata se impliquen en la operación migratoria tanto como los que cooperan con ellas (cfr. Chaumont, 2009, p. 96) ${ }^{30}$, este estatuto particular prevé, como principal recomendación del Comité, la figura reina de la expulsión (de prostitutas extranjeras) -o la alternativa voluntaria de la repatriación-, que se propone bajo el eufemismo de velar por su protección como víctimas ${ }^{31}$; se subraya, por la misma razón, la conveniencia de disponer de lugares de detención temporal en los que encerrar a las migrantes que esperan la ejecución de la orden de expulsión (Cuarto periodo de sesiones -cfr. Chaumont, 2009, p. 256-) $)^{32}$.

A la vez, en un momento histórico de cierre de fronteras, comienzan a complicarse los procesos burocráticos para los migrantes, la incertidumbre aumenta a la par que la discrecionalidad administrativa en la obtención de visados, un estado de cosas que se concibe también como instrumento disuasorio o de contención de flujos migratorios de poblaciones no cualificadas y empobrecidas (cfr. Chaumont, 2009, p. 260).

Es éste, pues, el ideario del Comité especial de expertos sobre la nueva visión de Trata internacional de personas. El diseño de sus medidas represivas no cayó en saco roto: sólo quedaba el paso de consolidarlo en instrumentos convencionales bajo los auspicios de la Sociedad de Naciones, dejando un legado para la futura Organización de Naciones Unidas.

\section{Resultados: Convenio para la represión de la trata de personas y de la explotación de la prostitución ajena (1949) y su funcionalidad como instrumento de represión de flujos migratorios}

La retórica del Comité especial de expertos fue la referencia que inspiró la necesidad de arbitrar un instrumento convencional que garantizara el compromiso internacional de llevar a cabo las líneas claves de combate y prevención de la Trata internacional de personas. El nuevo marco normativo internacional sobre la Trata de personas tomó forma, en un primer momento, en el Convenio relativo a la represión de la trata de mujeres mayores de edad, de 11 de octubre de 1933, que

\footnotetext{
${ }^{30}$ Ante una operación migratoria de estas características, se explica por qué esta modalidad de "víctimas" no denuncien la "trata".

${ }^{31}$ La expulsión de prostitutas extranjeras fue subrayada como principal recomendación en la Primera parte del Informe, y debatida en el Cuarto periodo de sesiones tras ser cuestionada en el período anterior por el experto francés, F. Hennequin. Cfr. Chaumont, 2009., pp. 252, 253, 255.
} 32

Revista del Laboratorio Iberoamericano para el Estudio Sociohistórico de las Sexualidades 184 https://doi.org/10.46661/relies.XXXX 
encarna la represión de todo desplazamiento de mujeres adultas que encuentran en la prostitución una vía para migrar, desligándose significativamente del Convenio precedente de 1921: aplica a las mujeres migrantes mayores de edad (imayores de 21 años!) el régimen de la minoría de edad para invalidar definitivamente su capacidad de consentir en el ámbito de la prestación sexual. En otras palabras, se las discapacita en un terreno que simultáneamente desaparece de los cuadros posibles laborales.

Artículo 1. Deberá ser castigado quien, para satisfacer pasiones ajenas, reclu te o seduzca, aun con su consentimiento, a una mujer o joven mayor de edad para ejercer la prostitución en otro país, aun cuando los diversos actos que sean los elementos constitutivos del delito se hayan realizado en distintos países. La tentativa de delito y, dentro de los límites legales, los actos preparatorios, también serán punibles.

Bajo el mismo eje, y ahora en las postrimerías de la Segunda Guerra Mundial, el ideario del Comité especial de expertos se consolida en el instrumento jurídico internacional que se convertiría en el broche de oro, el modelo de referencia sobre la materia, bajo los auspicios de la Asamblea General de la Organización de Naciones Unidas: el Convenio para la represión de la trata de personas y de la explotación de la prostitución ajena, de 2 de diciembre de 1949 (Resolución 317, IV) da un paso más.

Su Artículo 1 establece el compromiso de los Estados parte de "castigar a toda persona que, para satisfacer las pasiones de otra: 1) Concertare la prostitución de otra persona, aun con el consentimiento de tal persona; 2) Explotare la prostitución de otra persona, aun con el consentimiento de tal persona".

Aunque por vía protocolaria muestra la voluntad de integrar ("fusionar") los convenios internacionales anteriores sobre la materia $-1904^{33}, 1910^{34}, 1921^{35}, 1933^{36}-$, el de 1949 toma el testigo de un proyecto convencional inmediatamente precedente (1937), simbolizando el fin de la esencia de la trata de esclavos, que se ha diluido en el camino: ya no se exige indefectiblemente, para designar la Trata, la presencia de elementos de abuso o coerción que doblegan la voluntad de la víctima en relación con la prestación sexual.

Asumiendo los dogmas del abolicionismo imperante, y a través del arma penal ${ }^{37}$, el Convenio de 1949 refleja la política de neutralización de los factores de atracción de desplazamientos transnacionales de personas prostitutas extranjeras ("de uno u otro sexo", apostilla el Art. 17). Ahonda en la criminalización del entorno de la prostitución hasta incidir en la prohibición de la prostitución misma: criminaliza, bajo la voz "trata", todo comportamiento de terceros que favorezca el ejercicio de la prostitución (integra también la modalidad de prostitución migrante voluntaria), porque es favorecer la idea de la prostitución como oportunidad de colocación para migrar. Bajo ese mismo eje, incluye, como novedad, dentro del catálogo criminal, al usuario demandante de servicios sexuales: un nuevo protagonista se añade al amplio abanico "preventivo" de la agenda política internacional sobre la Trata.

El hilo argumental sigue siendo considerar irrelevante en todo caso el consentimiento de la mujer mayor de edad, su capacidad de decisión tanto en la operación transfronteriza como en la

\footnotetext{
${ }^{33}$ Modificado por el Protocolo aprobado por la Asamblea General de las Naciones Unidas el 3 de diciembre de 1948.

${ }^{34}$ Modificado por el Protocolo aprobado por la Asamblea General de las Naciones Unidas el 3 de diciembre de 1948.

${ }^{35}$ Modificado por el Protocolo aprobado por la Asamblea General de las Naciones Unidas el 20 de octubre de 1947.

${ }^{36}$ Modificado por el Protocolo aprobado por la Asamblea General de las Naciones Unidas el 20 de octubre de 1947.

${ }^{37}$ Vid., especialmente, Art. 17, que establece el compromiso internacional de desarrollar una legislación de "combate" contra la trata internacional de personas "para fines de prostitución", llamando a la cooperación internacional para su persecución, tanto en los países de origen, de destino como de tránsito.
}

Revista del Laboratorio Iberoamericano para el Estudio Sociohistórico de las Sexualidades 185 https://doi.org/10.46661/relies.XXXX 
prestación de servicios sexuales por cuenta propia o ajena, que se aparta definitivamente de la esfera de emancipación laboral: un cambio de formato cualitativo de víctimas extraordinariamente lejano de la trata de esclavos que sirve para desarrollar estrategias de represión de ese perfil migratorio de mujeres.

Se logra así, especulando con el valor de la dignidad humana, instituir un estigma de peligrosidad social en torno de la prostitución: como proclama el Convenio de 1949 en el inicio del Preámbulo, "la prostitución y el mal que la acompaña, la trata de personas para fines de prostitución (...) ponen en peligro el bienestar del individuo, de la familia y de la comunidad" (cfr. Royo, 2003, p. 39 -cursiva añadida-). Transforma a las mujeres, en todo caso, en víctimas de Trata-prostitución, o viceversa, que necesitarán "rehabilitación y adaptación social” (Art. 16) 38.

El Convenio de 1949 es el retrato de la política criminal orientada a la contención, en clave de "combate" (como señala su Art. 17), de la presencia de prostitutas extranjeras en otros territorios. A la decisión de discapacitar a la mujer adulta en esta esfera -victimizándola-, se suma un conjunto de instrumentos disuasorios y policiales, bajo el recurrente principio de protección de las víctimas (Art. 17). Insta a la organización de campañas mediáticas advirtiendo "el peligro de dicha trata", promueve la cooperación internacional para su persecución tanto en los países de origen, de destino como de tránsito, mediante la vigilan cia en los puestos fronterizos (estaciones de ferrocarril, aeropuertos, puertos marítimos), "y en otros lugares públicos", para detectar a las "personas que prima facie parezcan ser culpables o cómplices de dicha trata o víctimas de ellas". Asimismo, impone actividades de "inspección de las agencias de colocación, a fin de impedir que las personas que buscan trabajo, en especial las mujeres y los niños, se expongan al peligro de la prostitución" (Art. 20).

E instituye, por primera vez, la medida "reina" contemporánea: la expulsión de las nuevas víctimas mujeres inmigrantes (Art. 19). Una nueva forma de criminalización. Nuevo objetivo conseguido.

Frente a los instrumentos internacionales anteriores, el Convenio de 1949 prevé expresamente la figura de la expulsión de las víctimas de Trata, cuando "se ordenare conforme a la ley" (Art. 19), probablemente pensada para las hipótesis de consentimiento en la operación migratoria y en el ejercicio del trabajo sexual. Incluye también la modalidad de repatriación eventual (Arts. 18, 19), un retorno voluntario, o bien a iniciativa de "personas que tengan autoridad" sobre la víctima desplazada, previo acuerdo con el Estado de destino, cuyos costes deben ser sufragados por ella, salvo imposibilidad para afrontarlos ("víctimas indigentes"), en cuyo caso, se distribuirán entre el país de residencia (el viaje hasta la frontera, el puerto de embarque o el aeropuerto más próximo) y el país de origen (Art. 19).

Cabe observar que las medidas mencionadas por el Convenio de 1949 -salvo la expulsión obligatoria de víctimas de Trata- provenían específicamente del Convenio de 1904 (véanse los Arts. 2, 3 y 6), que, junto al de 1910, se fusionó, actualizó y complementó con ocasión del Convenio de la Sociedad de Naciones de 30 de septiembre de 1921 para la represión de la trata de mujeres y niños. Ahora bien, el objeto de preocupación de aquellos tres instrumentos convencionales sobre la Trata internacional lo constituían mujeres "de las que se ha abusado o se les ha forzado", señalaba el

\footnotetext{
${ }^{38}$ Dado que se entiende que la prostitución, en sí, es incompatible con la dignidad. Cfr. Maqueda Abreu, 2017, pp. 76 ss. Precisamente, en la discusión del Convenio intervino el jurista norteamericano B. Johnson, que fue miembro del Comité especial de Expertos de la Sociedad de Naciones y director de la sección jurídica de la Asociación de Higiene Social americana. En esta ocasión, colaboró en calidad de delegado de la Oficina Internacional para la represión de la trata de mujeres y niños. Naciones Unidas, Consejo económico y social, Comisión sobre cuestiones sociales, Cuarta Sesión, Nueva York, 9/5/1949, E/CN.5/SR.78, p. 5. Cfr. Chaumont, 2009, p. 16.
}

Revista del Laboratorio Iberoamericano para el Estudio Sociohistórico de las Sexualidades 186 https://doi.org/10.46661/relies.XXXX 
Preámbulo de 1904, es decir, la Trata como antesala de explotación en condiciones similares a la esclavitud. El Convenio de 1949, en cambio, cubre un escenario distinto, una modalidad de prostitución migrante voluntaria.

En suma, es así cómo el discurso político de la Trata de personas se vinculó estrechamente a las cuestiones de la inmigración, fundiéndose en ellas, transformando un fenómeno humano de dimensión socioeconómica en un asunto penal, y la concepción de la Trata en paradigma del control de flujos migratorios contemporáneos de perfiles (laborales) económicos no cualificados (véase Pérez Alonso, 2008, p. 239; 2019, pp. 65 ss; Lara Aguado, 2012, pp. 75 ss; Pérez Cepeda, 2004, p. 22; Cugat Mauri, 2006, p. 77; Daunis Rodríguez, 2012, pp. 94 ss; Villacampa Estiarte, 2019, pp. 34).

Las iniciativas ideadas por el Comité especial de expertos de la Sociedad de Naciones para erradicar y prevenir la Trata (no la esclavitud) revierten, bajo la mirada cómplice de las posturas abolicionistas, no sólo contra las mujeres-trabajadoras sexuales-nuevas víctimas de Trata-inmigrantes clandestinas. Encarnan un modelo precursor de las políticas represivas anti-inmigratorias y aporofóbicas en Europa desde la última década del siglo XX (cfr. Chaumont, 2009, pp. 13 ss, 19 ss) ${ }^{39}$ -flujos con destino a Europa desde el continente africano y latinoamericano, o dentro de Europa, desde el este y el sur hacia el norte- en el que las palabras clave habitan en la exclusión de inmigrantes: mano de obra extranjera no cualificada, prohibición de entrada, expulsión, devolución en frontera, centros de internamiento de extranjeros. Un lenguaje normalizado en las democracias europeas del siglo XXI (cfr. Pomares Cintas, 2014, pp. 125 ss).

Se construye un sistema que, al tiempo que blinda las fronteras, que establece trabas para la entrada al territorio de mano de obra no cualificada y empobrecida, abre y alienta una industria, la de la inmigración o tráfico de personas (cfr. Maqueda Abreu, 2002, p. 260; García Arán, 2006, pp. 3, 1011; 2017, pp. 661, 662; Hava García, 2006, pp. 84, 86; Cugat Mauri, 2006, p. 77) en torno a la idea del traslado a otro país como un "bien preciado" (cfr. García Arán, 2006, p. 22) -la facilitación del cruce de fronteras o burla de los controles fronterizos, y/o colocación en el país de destino.

Se asiste, pues, a una nueva visión de Trata de personas desvirtuada como antesala de un destino explotador esclavo, con una funcionalidad integrada en las estrategias de control de flujos migratorios contemporáneos de perfiles (laborales) económicos no cualificados, vinculados a los dramáticos efectos de la desigualdad, marginación y exclusión socioeconómica de amplios sectores de población, que se derivan de la globalización del modelo único económico neoliberal.

Y es así cómo se produce un cambio de formato cualitativo de víctimas extraordinariamente lejano de la trata de esclavos y, por ende, lejano de un destino explotador identificado con la esclavitud (Pomares Cintas, 2019). Un estado de cosas provocado por un ejercicio antológico de "deshonestidad intelectual", que retrata el ideario del Comité especial de expertos de la Sociedad de Naciones (Chaumont, 2009, pp. 12 ss., 279) ${ }^{40}$. En cualquier caso, como sostiene Álvarez García, el recurso a maniobras terminológicas y la falta de rigor que distorsionan algunos discursos no son una excepción en el seno de organismos internacionales (Álvarez García, 2019, pp. 46 ss).

\section{Reflexiones sobre el impacto del discurso de la Trata de personas en la actualidad}

Estos datos históricos no solo reflejan una realidad que se transmuta en una época determinada y que regresa luego al abrigo de los archivos. Hoy se reconoce que los flujos migratorios de cuadros no cualificados y empobrecidos no cesarán porque los factores que los impulsan "tienen vocación de permanencia" (Comunicación de la Comisión europea, 2016, sobre el Primer informe de situación

\footnotetext{
${ }^{39}$ Y, a su vez, se inscribe dentro de las estrategias político-criminales aporofóbicas. Cfr. Terradillos Basoco, $2019, \mathrm{pp}$. 351 ss.

${ }^{40}$ En esta línea, Solana Ruiz, 2011, p. 917.
}

Revista del Laboratorio Iberoamericano para el Estudio Sociohistórico de las Sexualidades 187 https://doi.org/10.46661/relies.XXXX 
sobre el Marco de Asociación con terceros países en el contexto de la Agenda Europea de Migración). Van a seguir viniendo... (Naïr, 2006).

El discurso vuelve hoy sobre sus pasos, centrándose de nuevo en clave de neutralización de los factores de atracción de esos desplazamientos transnacionales molestos. El Parlamento europeo toma el testigo de aquel Comité de la Sociedad de Naciones y recupera su legado, manteniendo vivo el Convenio de 1949. El planteamiento plasmado en la Resolución, de 26 de febrero de 2014, sobre explotación sexual y prostitución y su impacto en la igualdad de género, es muy similar. La prostitución está condenada a ser rehén permanente de una visión de Trata de seres humanos cuyo epicentro se sitúa en la idea de contención de flujos migrantes de perfiles socioeconómicos bajos (Borges y Gebrin, 2014) y no en la prevención de un delito-fin: la explotación en condiciones asimiladas a la esclavitud. Una herramienta penal, la de la Trata, que se inscribe expresamente en el marco de las "políticas sobre controles en las fronteras, asilo e inmigración", destinadas a "garantizar, en todo momento, una gestión eficaz de los flujos migratorios" (arts. 79.1, 79.2 d) Tratado de Funcionamiento de la Unión Europea). Es por ello que se insiste en erradicar a toda costa, a nivel europeo, concebir el ejercicio de la prostitución bajo la idea de trabajo: como se declara expresamente en la citada Resolución, hay que "evitar la idea de que la prostitución puede ser una solución para las mujeres migrantes en Europa". Para envolver esta idea en "papel de trata", se recurre a una triple identificación que prescinde de categorías conceptuales y realidades: prostitución=Trata=esclavitud, especulando así, de nuevo, con la dignidad de las mujeres ${ }^{41}$. El ideario de los movimientos abolicionistas, cargado seguramente de buenas intenciones, se filtra instrumentalizado, ahora como entonces, para el logro de propósitos que trascienden la cuestión encabezada por los argumentos de la violencia de género: coadyuva, bajo su mirada cómplice, al desarrollo de políticas represivas de control de fronteras en el territorio UE.

Acaparando el discurso de la prostitución bajo estos parámetros reduccionistas, sólo se consigue abrir un profundo mar de especulaciones y conflictos. No sólo ha detenido drásticamente, como si fuera una cuestión de orden público, todo debate serio, sereno y reflexivo sobre un posible modelo que parta del carácter laboral de los servicios sexuales prestados voluntariamente ${ }^{42}$. También entorpece analizar con rigor el rostro y las aristas de la esclavitud de hoy, sus formas de manifestación, los rasgos que la identifican, los criterios para su detección, la identificación de las víctimas. Porque hay otros rehenes de este discurso reductor de la Trata de personas, bajo la complicidad, consciente o no, de las corrientes abolicionistas: no permite preguntar ni cuestionar aquello que promueve las graves explotaciones humanas: la mercantilización global de los derechos sociales y económicos, la insuficiencia de los canales para la migración regular, los deficientes sistemas de migración laboral, los modelos de contratación -solo en el país de origen- en sectores productivos no cualificados: así, el tándem autorización de trabajo y residencia, los visados vinculados a una sola actividad, a un solo empleador, a una sola porción territorial. Porque ciertamente en estos sectores productivos se acusa la precariedad de las opciones u oportunidades laborales y recursos para las mujeres-inmigrantes, una posición de clara desventaja en el mercado de trabajo. Precisamente, respecto de esta concreta cuestión, aquel Comité especial de Expertos de la Sociedad de Naciones reconoció la importancia de afrontarla, pero mira a otro lado con el

\footnotetext{
41 Véase la réplica a la Resolución del Parlamento europeo, de 26 de febrero de 2014, sobre explotación sexual y prostitución y su impacto en la igualdad de género, objetando la falta de rigor de la información que maneja, "A Critique of the "Report on Prostitution and Sexual Exploitation and its Impact on Gender Equality", https://www.nswp.org/resource/critique-the-report-prostitution-and-sexual-exploitation-and-its-impact-genderequality.

${ }^{42}$ Sobre los distintos modelos de reglamentación, Olarte Encabo, 2017, pp. 519 ss. Vid. Giménez Merino, 2018, pp. 25 ss.
}

Revista del Laboratorio Iberoamericano para el Estudio Sociohistórico de las Sexualidades 188 https://doi.org/10.46661/relies.XXXX 
argumento de afectar a "un vasto problema de orden económico" que queda fuera de sus prerrogativas ${ }^{43}$. Las respuestas a estos factores, excusadas por trascender las competencias en relación con la persecución-prevención de la Trata de personas, son siempre una interrogante pendiente que elude, en definitiva, poner en tela de juicio el mantra neoliberal que nos envuelve y deja innumerables víctimas en el camino.

${ }^{43}$ Cfr. deliberaciones en el Quinto período de sesiones; Primera parte del Informe.

Revista del Laboratorio Iberoamericano para el Estudio Sociohistórico de las Sexualidades 189 https://doi.org/10.46661/relies.XXXX 


\section{Bibliografía}

Álvarez García, F. J. (2019). Naciones Unidas contra las mujeres: entre la ignorancia y la soberbia (a propósito de la elaboración de un nuevo Código Penal para Honduras y las propuestas efectuadas por distintas oficinas de NNUU en materia de violencia de género y aborto), Eunomía. Revista en Cultura de la Legalidad 15, pp. 46-84.

Attwood, R. (2016). Looking Beyond "White Slavery": Trafficking, the Jewish Association, and the dangerous politics of migration control in England, 1890-1910, Anti-Trafficking Review 7, pp. 115138.

Borges, P. C. y Gebrin, L. M. (2014). Combate ao tráfico de mulheres ou controle migratório da prostituição?. En Cruz-Zúñiga, P. y Cordero-Ramos, N. (eds.), Análisis, retos y propuestas en torno a la trata de personas, Sevilla, Aconcagua libros, pp. 151-176.

Caruso Fontán, M. V. (2011). Sobre la criminalización de las actividades relacionadas con la prostitución consentida, Revista de Derecho y Proceso penal 25, pp. 31-44.

Chaumont, J.-M. (2009). Le mythe de la traite des blanches. Enquête sur la fabrication d'un fleau. Paris: La Découverte.

Cugat Mauri, M. (2006). Normativa internacional y derecho comparado, En M. García Arán (coord.), Trata de personas y explotación sexual, Granada: Comares.

Daunis Rodríguez, A. (2012). Cuestiones clave de la prostitución y trata de personas. Aproximación al caso andaluz, En A. Iglesias Skulj y L.Ma Puente Aba (coords.), Sistema penal y perspectiva de género: trabajo sexual y trata de personas, Granada: Comares, pp. 91-120.

Flexner, A. (1914). Prostitution in Europe, New York: The Century Co.

Fontana, J. (2017). El siglo de la revolución, Una historia del mundo desde 1914, Barcelona: Planeta ed. Crítica.

García Arán, M. (2006). Los tipos penales acogedores del tráfico de personas. En M. García Arán (coord.), Trata de personas y explotación sexual, Granada: Comares.

García Arán (2017). Trata de personas y regulación de la prostitución. En Pérez Alonso (dir.), El Derecho ante las formas contemporáneas de esclavitud. Valencia: Tirant lo Blanch, pp. 655-675.

Giménez Merino, A. (2018). El cuerpo de las trabajadoras sexuales como campo en disputa: la controversia sobre el derecho a decidir. En C. Barbosa Abreu y F. Carvalho Leite/M. Messias Peixinho (orgs.), Temas de direitos humanos 1, pp. 25-42.

Gritner, F.K. (1990). White Slavery. Myth, Ideology, and American Law, New York: Garland.

Hava García, E. (2006). Trata de personas, prostitución y políticas migratorias, Estudios penales y criminológicos 26, pp. 81-124.

Iglesias Skulj, A. (2012). Prostitución y explotación sexual: la política criminal del control del cuerpo femenino en el contexto de las migraciones contemporáneas (el caso de España), Investigaciones: Secretaría de Investigación de Derecho Comparado, 1, pp. 13-25.

Kneeland, G. J. (1917). Commercialized Prostitution in New York City, New York: The Century Co., ed. actualizada.

https://archive.org/stream/commercializedpro0kneeiala/commercializedpro0kneeiala djuu.txt. Último acceso enero 2020 
Lara Aguado, Á. (2012). La trata como grave violación de derechos humanos: incoherencias entre la concepción de la trata como atentado a los derechos humanos y su regulación a nivel interno e internacional, En Á. Lara Aguado (dir.), Nuevos retos en la lucha contra la trata de personas con fines de explotación sexual. Un enfoque interdisciplinar, Navarra: Aranzadi, pp. 45-107.

Maqueda Abreu, M. L. (2002). “Una nueva forma de esclavitud: el tráfico sexual de personas”. En P. Laurenzo Copello (coord.), Inmigración y Derecho penal, Valencia: Tirant lo Blanch, pp. 255-272.

Maqueda Abreu, M. L. (2007). La trata de mujeres para explotación sexual. En R. Serra Cristóbal, R. (coord.), Prostitución y trata. Marco jurídico y régimen de derechos, Valencia: Tirant lo Blanch, pp. 295-306.

Maqueda Abreu, M. L. (2009). A propósito de la trata y de las razones que llevan a confundir a I@s inmigrantes con esclav@s, En J.C. Carbonell Mateu, J.L. González Cussac y E. Orts Berenguer (dirs.), Constitución, derechos fundamentales y sistema penal (semblanzas y estudios con motivo del sesenta aniversario del profesor Tomás Salvador Vives Antón, Valenia: Tirant lo Blanch, pp. 12451260.

Maqueda Abreu, M. L. (2017). La prostitución: el "pecado" de las mujeres, Cuadernos electrónicos de Filosofía del Derecho 35, pp. 64-89.

Naïr, S. (2006). Y vendrán...: las migraciones en tiempos hostiles. Barcelona: Bronce

Olarte Encabo, S. (2017). La prostitución voluntaria: ¿una forma de esclavitud o de ejercicio de libertad personal, de trabajo y de empresa?". En El Derecho ante las formas contemporáneas de esclavitud. Valencia: Tirant lo Blanch, pp. 517-567.

Pérez Alonso, E. (2008), Tráfico de personas e inmigración clandestina. (Un estudio sociológico, internacional y jurídico penal). Valencia: Tirant lo Blanch.

Pérez Alonso, E. (2019). "Marco normativo y política criminal contra la trata de seres humanos en la Unión Europea". En E. Pérez Alonso y E. Pomares Cintas (coords.), La trata de seres humanos en el contexto penal iberoamericano, Valencia: Tirant lo Blanch, pp. 63-113.

Pérez Cepeda, A. (2004). Globalización, tráfico internacional ilícito de personas y Derecho penal, Granada: Comares.

Pomares Cintas, E. (2014). La Unión europea ante la inmigración ilegal: la institucionalización del odio, Eunomía. Revista en Cultura de la Legalidad 7, pp. 143-174.

Pomares Cintas, E. (2019). "Hacia una coalición regional sudamericana contra la trata de personas: protocolo regional de buenas prácticas en torno al eje de persecución del delito de trata de personas y modalidades de explotación asimiladas a la esclavitud", en E. Pérez Alonso y E. Pomares Cintas (coords.), La trata de seres humanos en el contexto penal iberoamericano. Tirant lo Blanch, Valencia, pp. 400-431.

Royo, E. (2003). "Prostitución sin fronteras: derechos humanos versus derecho del hombre", En A. Bolaños, N. Parrón, E. Royo y J.Ma Santana, Debate sobre prostitución y tráfico internacional de mujeres. Reflexiones desde una perspectiva de género. Médicos del mundo. Mayo. (http://pmayobre.webs.uvigo.es/pdf/debate prostitucion.pdf. Último acceso enero 2020.

Solana Ruiz, J.L. (2011). La trata de seres humanos con fines de explotación sexual: análisis conceptual e histórico, Actas del I Congreso Internacional sobre Migraciones en Andalucía. Granada: Instituto de Migraciones, pp. 915-923. 
Terradillos Basoco, J. M. (2019). Un sistema penal para la aporofobia. En G. Portilla Contreras/F.Velásquez Velásquez (dirs.), Libro Homenaje a Perfecto Andrés Ibáñez, Madrid: Dykinson, pp. 353- 364.

Villacampa Estiarte, C. (2012). Análisis de las políticas de criminalización de la prostitución. En A. Iglesias Skulj y L.Ma Puente Aba (coords.), Sistema penal y perspectiva de género: trabajo sexual y trata de personas, Granada: Comares, pp. 1-44.

Villacampa Estiarte, C. (2019). La trata de seres humanos: concepto y caracterización. En E. Pérez Alonso y E. Pomares Cintas (coords.), La trata de seres humanos en el contexto penal iberoamericano, Valencia: Tirant lo Blanch, pp. 21-62.

Zweig, S. (2001). El mundo de ayer. Memorias de un europeo. Barcelona: Ed. El acantilado. 